\title{
O PENSAMENTO FECUNDO: \\ ELEMENTOS PARA UMA RACIONALIDADE TRANSMODERNA
}

Luciano Costa Santos*

Para Ana Cecília Costa

"Eis o paradoxo: como modernizar-se e retornar às fontes?"

Paul Ricoeur

\begin{abstract}
RESUMO
Uma das principais marcas do contexto contemporâneo é o desgaste de ideais iluministas fundadores da modernidade, em decorrência da expansão planetária de um sistema civilizatório baseado na produtividade e competitividade. Esse transe histórico atinge a escola "ilustrada" moderna, instrumentalizada como banco de dados a serviço de demandas mercadológicas. Diante da encruzilhada "pós-moderna", propõe-se como perspectiva histórica o paradigma da transmodernidade, situado além da negação ou reafirmação da modernidade, e que consiste na reapropriação do legado científico e crítico da racionalidade moderna, a partir da revisita a fontes hermenêuticas por ela relegadas. Tais fontes, como as dimensões de transcendência, alteridade e tradição, propiciam uma fecundidade de sentido que a razão crítica não pode produzir por si mesma, e constituem uma reserva sapiencial ante o dissolvente pragmatismo pós-moderno.
\end{abstract}

Palavras-chave: Modernidade. Razão crítica. Pós-modernidade. Pensamento fecundo. Transmodernidade.

\begin{abstract}
FRUITFULTHOUGHT: ELEMENTS FORATRANSMODERN RATIONALITY

One of the main characteristics of the contemporary context is the deterioration of the illuminist founding ideals of modernity. This fact is due to the planetary expansion of a civilization system based on productivity and competitiveness. This historical trance reaches the modern "aesthetic" school which acts as database for market demanding. Facing the "postmodern" crossroad, we propose as a historical perspective the transmodernity paradigm that is beyond negation or confirmation of modernity. It consists of scientific and critical legacy appropriation of modern rationality through the relegated hermeneutical sources. These sources, as the dimensions of transcendence,
\end{abstract}

\footnotetext{
* Doutor em Filosofia pela Pontifícia Universidade Católica do Rio Grande do Sul (PUCRS), com estágio no Institut Catholique de Paris/Université de Poitiers. Professor Adjunto da Universidade do Estado da Bahia (UNEB). Professor do Programa de Pós-Graduação em Educação e Contemporaneidade (PPGEDUC). Pertence à Linha 1 (Processos Civilizatórios: Educação, Memória e Pluralidade Cultural) do Programa de Pós-Graduação em Educação e Contemporaneidade (PPGEDUC) da UNEB. Endereço para correspondência: Av. Araujo Pinho, nº 421, Cond. Edgar Degas, Apto. 601 - Canela. CEP: 40.110-150. SalvadorBA. lucostasantos1@gmail.com
} 
alterity and tradition, give fruitful meaning that cannot be given by critical reason itself, and they are considered a kind of sapience stockpile facing the weak postmodern pragmatism.

Keywords: Modernity. Critical Reason. Postmodernity. Fruitful Thought. Transmodernity.

\section{Modernidade}

Não é fácil tomar pé na densa cerração dos tempos atuais, e menos ainda vislumbrar a luz de um possível horizonte histórico rumo ao qual se destinariam nossas esperanças. Conforme o ângulo que se eleja, há quem entenda os nossos tempos como desdobramento, exacerbação ou desagregação do projeto civilizatório moderno, e nesse caso seríamos - respectivamente - "modernos", "hipermodernos" ou "pós-modernos", ou, quem sabe ainda, tudo isso ao mesmo tempo. Como quer que se chamem as águas revoltas em que navegamos, parece razoável partir do conceito de modernidade como chave hermenêutica na tentativa de decifrar o sentido e divisar as perspectivas que se abrem com a contemporaneidade.

Antes de erigir-se em paradigma que se impõe às mais diversas áreas de atuação humana, da economia à educação, o conceito de modernidade nasce colado à experiência histórica. É um conceito histórico-filosófico. Refere-se a uma nova era que se inaugura na Europa ocidental, a partir do século $\mathrm{XV}$, com sucessivos movimentos de ruptura e emancipação protagonizados, em vários níveis, pela classe dos mercadores de bens aglomerados nos centros urbanos - ou "burgos" - então em plena efervescência.

Em nível econômico, os "burgueses" rompem com a sujeição ao sistema feudal de produção, baseado na apropriação hereditária das terras, a partir da conquista do poder de acumular bens pela transformação técnica da Natureza. Momentos-chave dessa emancipação econômica são as revoluções Comercial (séc. XVI) e Industrial (séc. XIX), que impulsionam a conquista de novos mercados para além das fronteiras do Velho Mundo. Em nível político, o homem burguês se insurge contra o poder da aristocracia, legitimado por títulos hereditários de nobreza, abrindo caminho para a construção de uma ordem institucional pública pactuada pela sociedade civil, cujos principais momentos são as revoluções Gloriosa (séc. XVII) e Francesa (séc. XVIII), que fincam os fundamentos do Estado democrático e de direito. Em nível cultural, o homem moderno libera-se da tutela da Igreja, conquistando o poder de entender o mundo pelo livre exercício da razão, sendo marcos dessa emancipação mental o Renascimento (séc. XV) e o Iluminismo (séc. XVIII), que legam ao Ocidente o caldo de cultura humanista do qual viriam a surgir, dentre outras, instituições como o método científico e a escola pública.

Ruptura, emancipação, inovação: tais atitudes consubstanciam o espírito propulsor da era moderna, que preside a seus movimentos e momentos sem deter-se em nenhum deles, inaugurando um processo de incessante atualização histórica que configura a modernidade como projeto inacabado.

Fruto da emancipação da classe burguesa impulsionada pelo avanço técnico-científico, a modernidade traz em seu próprio advento a compreensão de si mesma como progresso face ao período histórico anterior, consolidando uma interpretação do tempo que tem o seu vetor axiológico fixado no futuro: doravante, o novo é sempre melhor; ser atual é estar à frente do que passou e o passado, em si mesmo, já é ultrapassado. Em suma, ser moderno é ser contemporâneo do futuro. Como afirma Paul Ricoeur (1968) em Civilização universal e culturas nacionais, no livro História e_Verdade, salta aos olhos a presença de certa linha progressiva na história das sociedades modernas, quer se tenha em conta a conquista de cada vez mais objetividade na ciência, eficácia na técnica, produtividade na economia, conforto no consumo, planificação no Estado, equanimidade no sistema jurídico, e assim por diante. Em certa medida, a racionalidade moderna - emancipada, autônoma - vem se tornando cada vez mais "razoável" de acordo com os seus pressupostos internos de objetividade, eficácia, produtividade, conforto, planificação e equanimidade. 
No entanto, o que caberia questionar - e deixamos a questão, por ora, em aberto - é se o fato do progresso, verificável em países ditos desenvolvidos, implica que o ideal de progresso esteja destinado a impor-se como horizonte às sociedades. De outro lado, tendo em vista os graves desarranjos sociais e ambientais decorrentes da expansão planetária da civilização moderna, importa ainda questionar se o próprio ideal de progresso é não somente viável (ou "sustentável"), mas apropriado para corresponder às mais exigentes aspirações humanas de sentido e convivência. Noutras palavras, o que está em jogo é a suposta equivalência de progresso e crescimento, ou modernização e humanização.

Não é fácil, porém, levar adiante tal tarefa de revisão paradigmática, pois isto obrigaria o pensamento a saltar para fora do campo de sentido que parece ser o único possível ou, ao menos, o único legítimo. Hegemônica nos espaços institucionais da ciência e da academia, a racionalidade moderna passa a confundir-se com a própria vida da razão, longe da qual não restariam senão sombras e incertezas, fanatismos e fantasias. No interior dessa jurisdição hermenêutica, questionar a objetividade como critério de sentido é correr o risco de cair no subjetivismo, questionar eficácia e produtividade como critério de valor é correr o risco de resignar-se ao inútil, questionar o progresso como sentido da história é correr o risco de retroceder ao "arcaico", questionar a equanimidade normativa como critério de justiça é correr o risco de ceder ao arbítrio, questionar, enfim, a modernidade como critério de civilização é correr o risco de tornar-se "bárbaro".

No entanto, assim como modernidade não é sinônimo de humanidade, mas apenas uma versão da aventura humana, a racionalidade moderna tampouco é a razão, mas um modo ou modelo desta, com a respectiva oferta de sua força e a impossibilidade de seus limites.

\section{2. "Crítica" da razão crítica}

Ora, o que antes de tudo caracteriza a racionalidade moderna é a decisão de não contar com outra fonte de sentido senão a que se origina do próprio sujeito. Se for assim, só pode fazer sentido o que não somente se apresenta ante a consciência do sujeito, mas o que provém de seu ato intencional.
Trata-se, portanto, não apenas de obrigar toda faculdade ou forma de conhecimento a prestar contas ante o crivo da razão reflexiva, mas de desautorizar, por princípio, a pretensão de inteligibilidade de qualquer forma de conhecimento constituída aquém ou além do campo de força da razão, seja esta científica, especulativa ou crítica.

Segundo Gadamer (2011), situa-se aqui o nó que leva o iluminismo (Aufklärung) a recusar a contribuição de revelação, tradição, autoridade e preconceito (ou, se quisermos, "pressuposto") como instâncias geradoras de sentido. Partindo da posição amplamente estabelecida de que cabe à razão reflexiva a prerrogativa de julgar a validade de qualquer conhecimento, o iluminismo conclui que todo conhecimento só pode ter o seu ponto de partida na reflexão. A partir daí, julga procedente cortar os fios que ligam a razão a pressupostos pré-reflexivos de ordem histórica ou cultural, preservando-a de qualquer contágio epistemológico indevido e lançando-a num percurso lógico linear e coerente, de certeza em certeza, de juízo em juízo, de argumento em argumento, de conclusão em conclusão. Com isso, a racionalidade iluminista livraria a razão de um círculo hermenêutico "vicioso" que justamente Gadamer - e, antes dele, Heidegger - assumem como virtuoso e levam às últimas consequências: aquele círculo segundo o qual a razão reflexiva já opera a partir de sentidos histórico-culturais dos quais lhe cabe apropriar-se para trazê-los à maior inteligibilidade possível. Assumir o círculo hermenêutico significa, portanto, reconhecer que a razão situa-se em um lugar e não tem como escapar da finitude. Se essa perspectiva parece degradar a razão - especialmente se considerada à luz ofuscante do Absoluto hegeliano, por exemplo -, de outro lado lhe confere a inaudita dignidade do que é vivo e mortal, reconhecendo que ela pertence a uma comunidade, traz à luz um tempo e mergulha num denso caldo de sentido, de tal modo insondável que não tem como vir de todo à luz na transparência do conceito.

De volta ao "nó" iluminista, o que leva a racionalidade moderna à destituição epistemológica de tradição, revelação, autoridade e preconceito é o fato de, ademais de prévias à reflexão, tais instâncias supostamente usurparem uma credibilidade que, de direito, pertenceria somente à razão, haven- 
do assim uma incompatibilidade de competências. Desse modo, a tradição revelada tenderia a ocupar o lugar da reflexão, a autoridade deslocaria o juízo, o preconceito substituiria a evidência.

De acordo com Gadamer (2011), porém, esses polos não são nem separados, nem incompatíveis como pretende a razão moderna. Em primeiro lugar, falta ao iluminismo suficiente radicalidade reflexiva para reconhecer o seu próprio "preconceito" quanto à suposta supremacia da razão reflexiva face às demais instâncias geradoras de sentido. Haveria, assim, um "preconceito" do iluminismo contra todo preconceito, com exceção do preconceito de que a "luz" da razão é superior a qualquer outra. De outro lado, embora pré-reflexivos, tradição, revelação, autoridade e preconceito não são necessariamente alheios a certa compreensão intuitiva, uma vez que a crença na revelação, o pertencimento à tradição, a obediência a uma autoridade e a aceitação do pressuposto por vezes supõem o reconhecimento implícito da lucidez que os torna persuasivos ou mesmo irrefutáveis. Por fim, mesmo atuando em distintas áreas de sentido - ou por isso mesmo -, razão e tradição carecem uma da competência da outra, sem o que a razão periga privar-se de sentidos seminais e a tradição, estacionar em um grau primário de compreensão que não faria jus à riqueza do que ela guarda.

Crença e crítica não disputam espaço hermenêutico. A crença dá o que a crítica não pode dar; a crítica tira o que a crença precisa perder para tornar-se mais dadivosa. No entanto, tal é a confusão instalada sob a longa hegemonia do paradigma iluminista, que a razão crítica, por assim dizer, atraiu a crença para si, dando lugar a uma inusitada crença na crítica, como se a reflexão sobre os limites da razão e a desconstrução de suas formas espúrias - competências da crítica - tivessem o poder de saciar a sede de sentido dos amantes da sabedoria. Tanto mais cáustica a crítica, tanto mais ardorosa a crença, até chegar-se ao extremo paradoxo de ortodoxos devotos dos mestres da suspeita, para os quais um pensamento se torna tanto mais digno de crédito quanto menos restar a ser desconstruído. No vórtice (já agora “pós-moderno”) dessa razão hipercrítica, não somente tudo o que é sólido, mas mesmo tudo o que é tenro se desmancha no ar, como se até a possibilidade de nascer e frutificar já fosse um atentado contra as suspeitas da razão.

Diga-se de passagem, para quem tem em torno de si uma civilização viçosa como a latino-americana, com a pletora de suas criações populares mestiças e tropicais, submeter-se, não propriamente à razão crítica, mas ao criticismo herdado de uma civilização vetusta como a europeia, não seria sintoma de... colonialismo cultural? Que acadêmico "emancipado", porém, estaria disposto a admiti-lo?

De desconstrução em desconstrução, à razão crítica foi afinal reservada a grandiosa tarefa de contribuir para "edificar o deserto" (UNGER, 2001, p. 19), âmbito de despojamento no qual só sobrevive o que permanece ligado às fontes, e que aqui se pode tomar como metáfora da possível passagem para uma nova ordem civilizatória mais além da modernidade. Nesses tempos de deserto, em que a racionalidade moderna parece haver atingido a exaustão após levar ao extremo o seu poder, não há como pretender uma possível superação da razão crítica por uma hipotética - e ainda mais engenhosa e rigorosa - crítica da razão crítica, que só nos precipitaria mais para dentro do vórtice do qual se espera escapar. A razão crítica não pode ser superada por qualquer novo investimento reflexivo, porque justamente lhe coube conduzir ao limite o esforço de construção/desconstrução reflexiva do sentido. Em tempo de deserto, já não se trata apenas de refletir mais, investir mais, capacitar, produzir, construir, desconstruir, reconstruir, progredir, mais (ou menos!), mas de preparar o dom de um novo começo. Trata-se, portanto, de submeter a razão moderna a um mortal rito de passagem pelo qual ela venha a renascer para além de seu poder e de sua impotência.

\section{Pensamento Fecundo}

A alternativa à razão crítica não é, portanto, de modo algum a razão acrítica - contradição nos termos-, mas o pensamento metacrítico ou fecundo. $\mathrm{O}$ meta ("além de"), referido no termo "metacrítico", indica a abertura da razão a instâncias hermenêuticas - tais como as mencionadas tradição, revelação e autoridade -, nas quais surpreende uma potência de sentido que, por seus próprios recursos reflexivos, ela não tem como prover a si mesma. Uma

1 A frase é atribuída a Nietzsche, sobre a "desertificação" do mundo contemporâneo. 
das características diferenciadoras do pensamento fecundo é, pois, a sua radical passividade, uma vez que o sentido não resulta da iniciativa intencional da consciência reflexiva, mas advém-lhe por dom. É encontrado. $\mathrm{O}$ pensamento fecundo recebe o logos daquele núcleo gerador de sentido a que pertence, escuta e reverencia. E aqui reside a sua segunda característica marcante, que é a de operar a partir de - e em relação com - uma dimensão outra, diante da qual o seu poder se detém. O pensamento fecundo é, assim, antes de mais nada, pensamento fecundado, ao fazer-se guardião de um sentido outro, novo, que o invoca e insta para vir à luz. Nessa perspectiva, e para continuar no rastro das metáforas que nos guiam, talvez se possa dizer que, enquanto cabe à razão crítica contribuir para enterrar ideias "semimortas" (ou "natimortas"), que entulham os discursos mas não geram acontecimento, o pensamento fecundo é chamado a favorecer a insurgência de sentidos que precisam vir à luz para que o mundo se renove. Sendo assim, é como se a tarefa do pensamento oscilasse entre tomar a sério e questionar, em última instância, ora o que precisa morrer, ora o que precisa nascer.

Opta-se, aqui, pelo termo "fonte" em vez, por exemplo, de "fundamento". O fundamento - metáfora arquitetônica - pode ser posto por alguém - o fundador -, tem o seu começo demarcável, é estável e atua como base sem, entretanto, influir naquele que sobre ele se sustenta; a fonte, ao contrário, brota de si mesma, tem origem insondável, é dinâmica, em permanente renovação, e comunica-se como dom àquele que dela vive, vivificando-o a cada instante. Em resumo, a imagem da fonte guarda as características do que é originário, gerativo, insondável, dinâmico, gratuito e dadivoso, e por isso parece melhor apropriada para servir de metáfora do princípio seminal (arké) que atua no pensamento fecundo.

Exemplos desse princípio hermenêutico gerador são, dentre tantos - e para ficar apenas com pensadores contemporâneos -, as categorias de "mundo da vida" (Lebenswelt) em Husserl, "ser" em Heidegger, "linguagem" em Gadamer, "mistério" em Gabriel Marcel, "carne" em Merleau-Ponty, "encontro" em Buber, "alteridade" em Levinas, "núcleo ético mítico" em Paul Ricoeur, "estar" em Rodolfo Kusch, para citar algumas das mais evocativas. Essas categorias têm em comum o deslocamento gravitacional levado ao "sol" da subjetividade moderna, que tudo constitui como objeto e reduz à própria medida e, no âmbito da polis, espraia a luz do "humanismo progressista" quando trata de prestar contas a parcelas esclarecidas da opinião pública.

A questão, para o pensamento metacrítico, não é a criticidade em si mesma, ou o seu suposto excesso. Especialmente na esfera das relações públicas, mas não apenas aí, a razão crítica é o mais eficaz preventivo contra abuso de poder, desigualdade de direitos, exploração e violência, e nunca será exigida o bastante em países como o Brasil, cuja pesada herança colonial expõe amplos setores da população à privação de recursos, supressão de direitos e falta de participação política. Criticidade nunca é demais. A questão é o modelo hegemônico de subjetividade autocentrada que erige a razão crítica em princípio soberano de sentido, confiando-lhe a prerrogativa pedagógica de presidir a formação do sujeito, a relação com os outros e a transformação do mundo, como se a autonomia de pensar por si (sapere aude!) e a consciência dos direitos próprios e alheios fosse o que de mais elevado se pudesse esperar do humano. A propósito de direitos, aliás, importa não perder de vista que a igualdade jurídica iluminista não nasce da solidariedade compartilhada, mas da concessão a todos os cidadãos de direitos que, em princípio, cada sujeito emancipado reivindica para si mesmo. Noutras palavras, a concepção iluminista de justiça tem como base uma antropologia individualista.

Não resta dúvida de que, sem razão crítica, não é possível emancipação, e sem esta não há como assegurar a dignidade humana. Isto posto, cabe indagar se a garantia da liberdade e dos direitos equivale ao ideal de vida humana ou constitui a necessária passagem rumo à sua realização. Sendo este o caso, o imperativo de emancipação estaria para a humanização, por exemplo, como a saúde para o esporte, o domínio da língua para a poesia, ou o respeito para a relação interpessoal. Fincados os marcos da cidadania em firmes alicerces jurídicos, estabelecidas as regras do jogo social com base na liberdade e igualdade universal de direitos, "resta" saber que sentido dar a felicidade, bem, mal, sexo, amor, amizade, família, morte, nascimento, valores, afetos, corpo, vício, transcen- 
dência etc.; resta, inclusive, saber que sentido dar às próprias liberdade, dignidade e justiça retiradas de seu enquadramento civil e jurídico, todas essas questões viscerais para as quais a racionalidade moderna reserva um tratamento raso ou evasivo, quando não as relega sumariamente ao campo da consciência "privada". Se as fontes hermenêuticas tradicionais foram interditadas como "irreflexivas" e "acríticas", de onde, afinal, haurir lucidez para dar sentido à vida e à morte?

A esse respeito, é bastante sugestivo que da velha França revolucionária um filósofo como Ferry (2007) tenha suscitado, no início deste século, o retorno a certa "espiritualidade laica" de matriz clássica greco-romana, com o propósito de enfrentar a crise de sentido da sociedade pós-metafísica a partir de uma perspectiva sapiencial que a comunidade acadêmica sequer parecia considerar digna de ser trazida ao debate público. Ainda mais significativo é que, na mesma França, nos anos 1970, após haver elaborado uma rigorosa desconstrução arqueológica da relação entre ciência e poder, ninguém menos que Foucault enceta uma guinada sapiencial em pleno reduto estruturalista. Valendo-se de uma releitura nietzschiana de filósofos helenistas, Foucault (2004) concebe a ética como estética da existência ou cuidado de si mesmo, tendo como base a compreensão da vida como obra de arte trabalhada pelo indivíduo a partir da vigilância criativa exercida sobre os próprios afetos e desejos.

Quaisquer que fossem as águas hermenêuticas aí em jogo, gregas ou outras, o sintomático nesses casos é, de um lado, a sede de sentido que leva à retomada de questões quase demitidas do campo filosófico; e, de outro, a busca de fontes sapienciais para além da razão crítica, por parte de filósofos que a manejam com maestria. Fica sugerido por esses exemplos que, reduzida a si mesma, a racionalidade moderna parece ter pouco a dizer sobre o enigma humano.

Dono de recursos, sujeito de saberes e direitos, desvencilhado de laços comunitários, o homem moderno não reconhece qualquer sentido extrínseco ao seu poder de pensar, produzir e gerir a vida por si mesmo, vindo a cristalizar-se a percepção de si como identidade autoconstitutiva e fundamento do real: penso, logo existo. Em última instância, ser eu é fundar a existência a partir da própria consciência. O ego cogito cartesiano não é, portanto, senão o correlato filosófico do poder - técnico, econômico, político e intelectual - que se libera no homem moderno.

\section{Pós-modernidade}

Um dos mais significativos paradoxos entranhados na modernidade reside, entretanto, no fato de que a emancipação do sujeito não se dá sem que ele mesmo acabe se sujeitando a mecanismos técnicos, econômicos e políticos que vão além de sua esfera individual de decisão e dele se apropriam como instrumento. Nos tempos atuais, consolida-se em nível planetário a expansão do sistema de acumulação econômica baseado na exploração da força de trabalho (a que Marx chama mais valia), articulado ao sistema tecnológico de exploração dos recursos naturais, sob a pressão de uma avassaladora força de apropriação que tudo submete a objeto de cálculo, uso e produção, e a que Heidegger (1995) denomina Gestell.

A expansão planetária desse sistema integrado de acumulação econômica e exploração tecnológica já não se encontra (se é que algum dia esteve) sob o controle de nenhum sujeito histórico. Trata-se, antes, de uma irresistível e ilimitada "mobilização total" (JÜNGER, 2002) que irrompe do coração da história, arranca e arrasta instituições seculares e cuja superação não parece sequer concebível, pois somente a custo se poderia imaginar a possibilidade de uma civilização futura pós-tecnológica e pós-industrial.

Contrariando uma perspectiva "humanista" que se estende até o século XIX, ciência (objetividade), técnica (eficácia), economia (produtividade) e política (planificação estatal) já não são meros recursos racionais à disposição de desígnios de emancipação, mas configuram hoje um único sistema civilizatório científico-técnico-econômico-político, cujo raio de atuação cobre todo o planeta e põe a seu serviço a sociedade toda de todas as sociedades. É a consumação da internacionalização compulsória desse sistema tecnológico-capitalista que se conhece com o nome de globalização, preferindo o pensador Milton Santos cunhá-lo de "globalitarismo" para sublinhar o seu aspecto totalitário, apontando como fatores de sua consti- 
tuição: a mais-valia globalizada como único motor da história; a unificação do sistema das técnicas por intermédio da informática; a sincronização do tempo mundial mediante técnicas de informática e comunicação; e a possibilidade de se tomar conhecimento de todas as sociedades do planeta (SANTOS, 2001).

Zygmunt Bauman chama "modernidade líquida" ao estágio atual da civilização moderna, para destacar o caráter fluido, volátil, desse poder global que não se fixa em parte alguma, invade todos os espaços e tende a desobstruir o que resiste à sua livre expansão (BAUMAN, 2001). Tal ação dissolvente não somente contribui para consumar o desmonte de estruturas tradicionais desconstruídas pela modernidade, mas atinge os fundamentos de sólidos marcos institucionais da própria modernidade. Assim, e para citar alguns dos mais representativos, o estado democrático e de direito recebe uma formatação "neoliberal" light que reduz sua ingerência em áreas vitais da sociedade; partidos políticos de fundo ideológico flexibilizam princípios em função de premências fisiológicas; escolas acomodam programas em vista da competitividade no mercado de trabalho; e a ciência desliga-se de ideais humanistas para converter-se em banco de dados à disposição de demandas mercadológicas (LYOTARD, 2008).

$\mathrm{Na}$ base dessa fragilizada arquitetura institucional legada pelas Luzes, o que se vê atingido é o modelo de racionalidade que lhe sustenta. Como se a própria razão moderna tivesse se tornado pesada demais para os fluídicos circuitos dos tempos atuais. Doravante, a ciência tende a se apossar da consciência, o cálculo esvazia a reflexão, a funcionalidade absorve o valor e a busca de bem-estar desloca o ideal de emancipação e outras "grandes narrativas" modernas (LYOTARD, 2008). Mesmo a razão crítica, com sua exaustiva exigência de lucidez, a desconfiar de Deus, do mundo e de si mesma, torna-se indesejável barreira ao fluxo do capital simbólico, e dá lugar a uma conveniente razão cínica, que se dispõe a tocar qualquer questão uma vez combinado que nenhuma deve ser levada a sério. Chega-se, assim, à imanência total do sentido - ou ao totalitarismo do sentido imanente $-{ }^{2}$, e o

2 Para um aprofundamento da categoria de "totalidade", ver Levinas ([198-?]). sujeito vem sujeitar-se ao sistema civilizatório que em suas origens parecia assegurar a sua libertação. Já não há novo mundo - utópico - a construir, nem velho mundo a pôr abaixo, apenas uma imensa vontade de poder, que é de todos e de ninguém, a pedir passagem.

Tendo em vista a dissolução de paradigmas modernos em curso, o mencionado Bauman (2001) e outros autores se referem aos tempos atuais como "pós-modernidade", na qual estaria em transe a passagem para outra ordem civilizatória.

Se na modernidade o sujeito emerge como indivíduo autônomo, em luta contra a opressão e a privação de direitos, na pós-modernidade encontra-se a reboque de um processo de atomização social que o isola dos demais e, no espelho da cultura da imagem, o torna cativo do culto a si mesmo. Eis o paradoxo: o eu moderno, emancipado, revolucionário, criador, elevado a princípio transcendental na categoria romântica de gênio, vê-se doravante hipertrofiado à condição de deus narcísico e, ao mesmo tempo, reduzido a simulacro de si mesmo. Se antes havia princípios a defender e causas por que lutar, agora se move à deriva do que o seduz: a consciência cede ao desejo, e a razão não tem mais força que a motivação.

Numa época acostumada a tantos obituários "morte de Deus", "fim da metafísica", cultura do "pós-humano" -, já não parece consequente proscrever a perspectiva ontoteológica sem renunciar às chamadas questões últimas. O reconhecimento da própria debilidade impõe-se, assim, como gesto mais radical do pensamento pós-moderno. ${ }^{3}$ Esvaziado de certezas e princípios, e abandonado aos próprios desejos, o sujeito oscila entre a segurança de posições fundamentalistas que lhe deem eixo em meio à dissolução geral, e a comodidade de soluções híbridas, à la carte, à medida de suas preferências e no limite de suas conveniências. Nessa perspectiva, a ética de oportunidade substitui a ética de princípios, numa flutuação de normas e valores em função dos interesses de cada um. ${ }^{4}$

Sem horizonte utópico a que destinar-se, a cultura pós-moderna leva à saturação sua ingênita dinâmica de superação. Premida pela ânsia de novidade, mas impossibilitada de gerar o novo,

3 Sobre o conceito de "pensamento fraco", ver Vattimo (1995).

4 Sobre o conceito de "ética de oportunidade", ver Susin (1996). 
inventa sucessivos prefixos paroxísticos, como "supra", "ultra", "mega", "super", "hiper", a fim de bater recordes de rendimento, sem, entretanto, lograr remediar o estéril vazio de sentido em torno do qual se agita. Contra as aporias da civilização pós-moderna e a insuficiência da razão cínica, sempre restam as exigências da razão crítica, a desconfiar de objetividade, funcionalidade, bem-estar, qualidade total, otimização e semelhantes relatos pós-modernos hegemônicos. Como vimos, porém, se à razão crítica é dado colaborar para "edificar o deserto", nem mesmo seus recursos bastam para fazer jorrar novas fontes.

\section{Conclusão: transmodernidade}

Diante dos impasses da civilização pós-moderna, há os que - "antimodernos" -vislumbram a saída na contramão da sociedade tecnológica, industrial e republicana. Outros, ao contrário "modernos" -, como Marx e Freud, apostam às últimas consequências na possibilidade de que a própria razão científica ou crítica venha a sanar as fraturas da civilização moderna e abrir-lhe o futuro. Outros, por fim - propriamente "pós-modernos" -, rendem-se à dissolução de instituições e ideais iluministas, resignam-se à implosão do tempo e assumem o sistema globalitário como seu reino.

Como toda época da história humana - aliás, como tudo o que é humano -, a pós-modernidade traz a ambiguidade em seu coração: se de um lado exacerba o desenraizamento existencial ${ }^{5}$ levado a cabo pelos tempos modernos, de outro contribui para abrir brechas na rígida ordem institucional moderna e dilatar a racionalidade que lhe subjaz, propiciando condições para o advento de um novo tempo histórico. Assim, do "pensamento fraco" pode-se abrir caminho ao senso do mistério; do culto narcísico do indivíduo, ao cultivo da interioridade; do refluxo da normatização à ética das relações interpessoais; da crise das utopias às transformações setoriais e locais; do retraimento do Estado ao protagonismo da sociedade civil, e assim por diante.

No entanto, para que os desertos pós-modernos sejam oportunidade de renascimento, é preciso

5 Sobre o conceito de "desenraizamento", ver Weil (2001). encontrar as fontes pelas quais renascer. Noutras palavras, é preciso encontrar a arké de um novo começo civilizatório. Se a contemporaneidade é o momento atual da história em que coexistem desdobramentos da modernidade, desconstruções pós-modernas e novas possibilidades latentes, trata-se de saber que perspectiva de contemporaneidade está à altura do futuro.

A nosso ver, a perspectiva de contemporaneidade a ser cultivada não é moderna, antimoderna ou pós-moderna, mas - com licença para o neologismo - transmoderna, isto é, aquela que não se posiciona nem em estrita continuidade ao projeto da modernidade nem (muito menos) contra este, mas busca ligá-lo a núcleos geradores de sentido que, de um lado, confiram sapiencialidade e responsabilização ética às suas conquistas científicas, tecnológicas, econômicas, jurídicas e políticas; e, de outro, atuem como eixo existencial ante a generalizada dissolução pós-moderna. Não se trata, portanto, de mera reafirmação ou dissolução da modernidade, mas de reapropriação desta a partir de fontes alternativas de sentido que ela ignora e não pode recuperar por seus próprios recursos.

Principais exemplos desses núcleos sapienciais são a transcendência ou relação com a gratuidade do mistério; a alteridade ou não indiferença pela diferença do Outro; e a tradição ou pertença à memória de uma comunidade. Reverenciar o mistério, se responsabilizar pelo Outro ou guardar a memória de um povo são gestos seminais que, por si mesma, a racionalidade moderna jamais teria como produzir.

De modo apenas indicativo, e para finalizar, assim resumiríamos os principais elementos de uma possível hermenêutica do paradigma transmoderno:

Sentido de emancipação, sem reduzir a esta a libertação humana;

Composição de liberdade e autoridade;

Sentido de autonomia do sujeito, sem confundi-la com independência;

Composição de autonomia e obediência;

Sentido de progresso, sem reduzir a este o crescimento humano;

Composição de progresso e tradição.

$\mathrm{Na}$ base do novo paradigma, subjaz a compreensão de uma racionalidade fecundada pelo sentido 
e de uma subjetividade despertada pelo outro. Em ambos os casos, o humano é visto em tensão para uma dimensão gratuita - a fonte de sentido ou o outro - que tanto mais o constitui quanto mais o ultrapassa.

\section{REFERÊNCIAS}

BAUMAN, Zygmunt. Modernidade líquida. Rio de Janeiro: Zahar, 2001.

FERRY, Luc. Aprender a viver. Rio de Janeiro: Objetiva, 2007.

FOUCAULT, Michel. Ditos e escritos - V. etica, sexualidade, política. Rio de Janeiro: Forense Universitária, 2004.

GADAMER, Hans-Georg. Verdade e método: traços fundamentais de uma hermenêutica filosófica. 11. ed. Petrópolis, RJ: Vozes, 2011.

HEIDEGGER, Martin. Língua de tradição e língua técnica. Lisboa: Vega, 1995.

JÜNGER, Ernst. A mobilização total. Natureza Humana - Revista do Grupo de Pesquisa em Filosofia e Práticas Psicoterápicas do Programa de Estudos Pós-Graduados em Psicologia Clínica da PUC-SP, São Paulo, v. 4, n. 1, p. 189-216, jan./jun. 2002.

LEVINAS, Emmanuel. Totalidade e infinito. Lisboa: Edições 70, [198-?].

LYOTARD, Jean-François. A condição pós-moderna. 10. ed. Rio de Janeiro: José Olympio, 2008.

RICOEUR, Paul. História e verdade. Rio de Janeiro: Forense, 1968.

SANTOS, Milton. Por uma outra globalização - do pensamento único à consciência universal. Rio de Janeiro: Record, 2001.

SUSIN, Luiz Carlos. Por uma ética da liberdade e da libertação - panorama das questões éticas hoje In: BEOZZO, José Oscar (Org.). Por uma ética da liberdade e da libertação. São Paulo: Paulus,1996. p. 13-71.

UNGER, Nancy Mangabeira. Da nascente à foz - o recado do rio. Campinas, SP: Cortez, 2001.

VATTIMO, Gianni. El pensamiento débil. Madrid: Cátedra, 1995.

WEIL, Simone. O enraizamento. Bauru, SP: EDUSC, 2001.

Recebido em 22.10.2012

Aprovado em 13.01.2013 